\title{
Molecular-Level Characterization of Oil-Soluble Ketone/Aldehyde Photo-oxidation Products by Fourier Transform Ion Cyclotron Resonance Mass Spectrometry Reveals Similarity Between Microcosm and Field Samples
}

Sydney F. Niles ${ }^{\dagger, \ddagger}$, Martha L. Chacón-Patiño ${ }^{\ddagger}$, Huan Chen ${ }^{\ddagger}$, Amy M. McKenna ${ }^{\ddagger}$ Greg T. Blakney ${ }^{\dagger}$, Ryan P. Rodgers* ${ }^{*}, 8^{*}$, Alan G. Marshall ${ }^{*}, \ddagger$

$\dagger$ Department of Chemistry and Biochemistry, 95 Chieftain Way, Florida State University, Tallahassee, FL 32306. United States

¥Ion Cyclotron Resonance Program, National High Magnetic Field Laboratory, Florida State University, Tallahassee, FL, 32310. United States

sFuture Fuels Institute, Florida State University, 1800 East Paul Dirac Drive, Tallahassee, Florida 32310. United States

Submitted to Environ. Sci. \& Technol. (MS \# es-2019-00908j): 12 February, 2019

Revised manuscript submitted:

24 April, 2019

\section{Supporting Information \\ (Three Pages)}

(Two Figures) 


\section{Ketone Isolation}

Figure SI-1

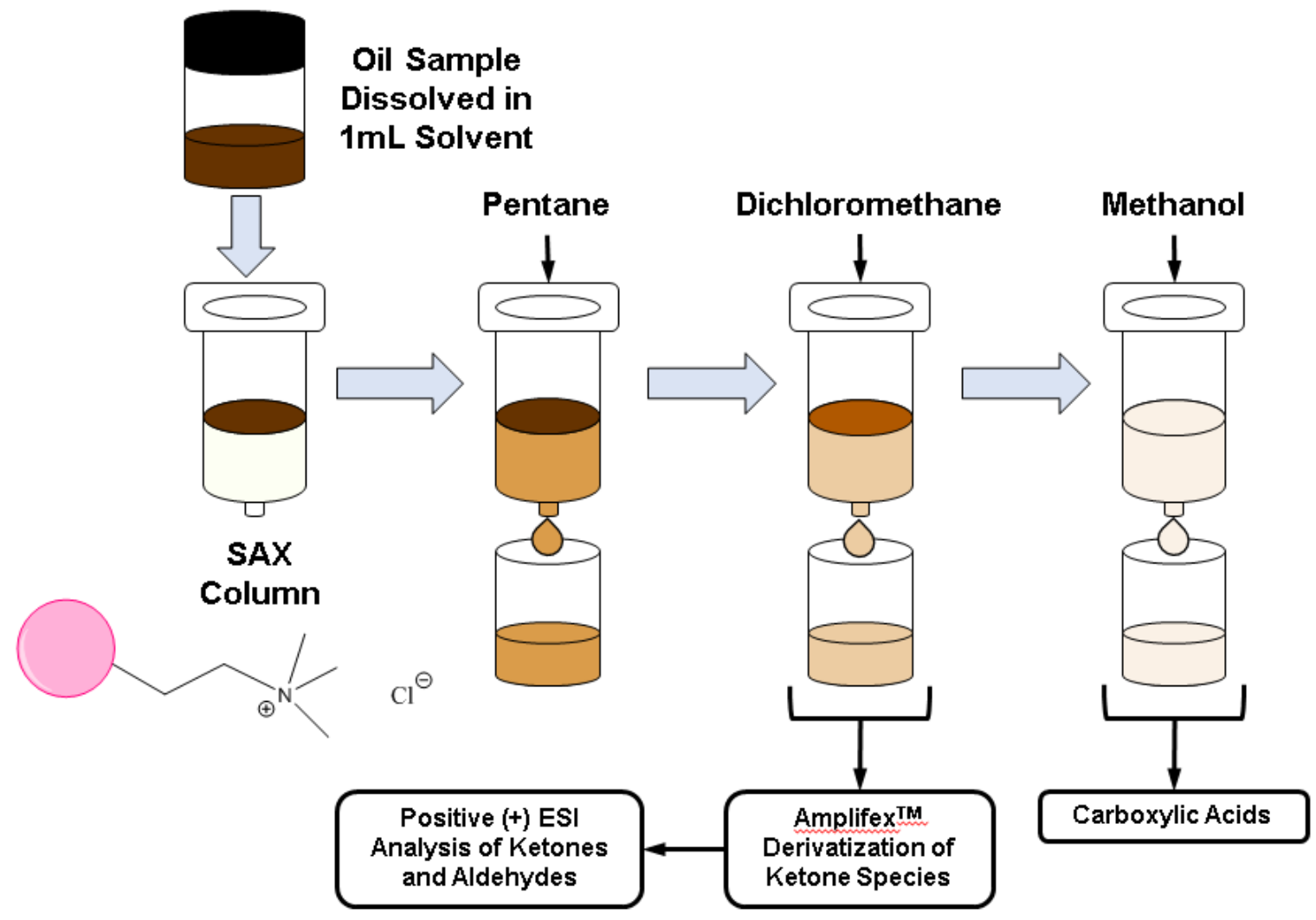

Figure S1. An SPE method which uses a strong-anion exchange to separate petroleum species by polarity allows for isolation of the ketone/aldehyde fraction prior to derivatization and analysis by (+) ESI 21T FT-ICR MS. 


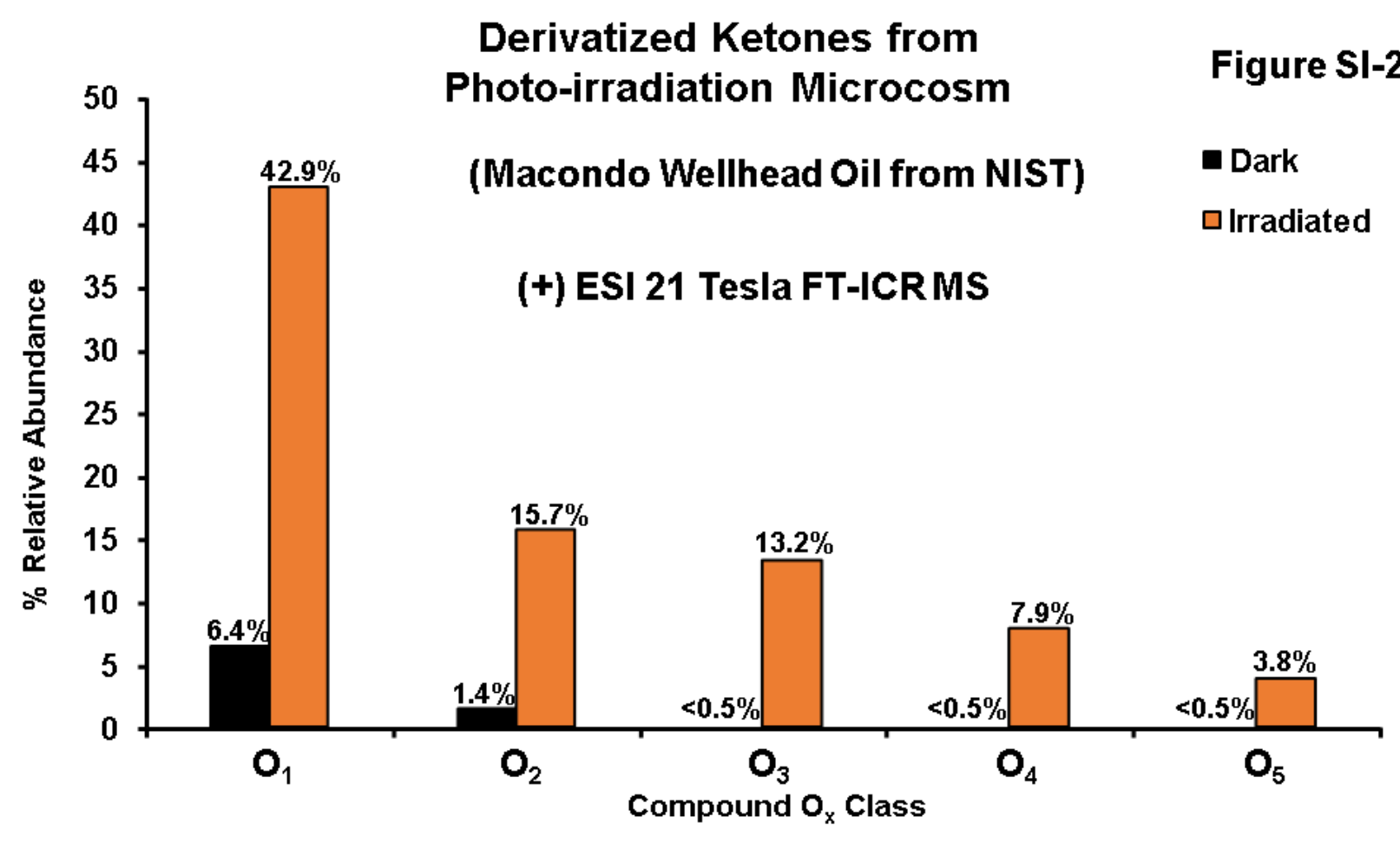

Figure S2. Relative abundances of $\mathrm{O}_{\mathrm{x}}$ heteroatom classes from dark (black) and labirradiated derivatized ketone/aldehyde fraction (orange) for the photo-irradiation microcosm. The irradiated sample exhibits higher relative $\mathrm{O}_{\mathrm{x}}$ abundances, as well as a higher number of oxygen atoms than the dark control. 